\title{
It Takes Two: Using Coleaders to Champion Improvements in Small Primary Care Practices
}

\author{
Kaia Gallagher, PhD, Paul A. Nutting, MD, MSPH, Donald E. Nease, Jr., MD, \\ Deborah G. Graham, MSPH, Aaron J. Bonham, MS, W. Perry Dickinson, MD, \\ and Deborah S. Main, PhD
}

Background: Making the kind of improvement changes necessary to move toward a patient-centered medical home will continue to challenge small, independent primary care practices. Here we describe further analysis of a successful program to understand the roles of coleaders of a change management process.

Methods: Through an improvement collaborative we trained 2 coleaders (a physician and a non-physician) from 16 small primary care practices to institute depression care improvements. These coleaders participated in 3 learning sessions that provided depression care content as well as skills to implement a change management strategy. Qualitative data were collected by observation during the learning sessions and through in-depth interviews conducted at baseline, between each learning session, at the end of the project, 6 months after the project ended, and, finally, 26 months after the project's end.

Results: Interview results with the coleaders affirmed that a team approach is a viable strategy for practice improvement. The 2 coleaders used their complementary skills, relationships, and credibility among the practice staff to implement and sustain practice improvements. In their differing roles, they varied in how they perceived barriers to change and how they assessed their team's progress.

Conclusions: Involving both a physician and a non-physician as coleaders enables improvement teams in small primary care practices to make progress both in the clinical content of their work and in the critical change management activities involved with creating a team, managing meetings, and coordinating work between meetings. Using a coleader structure enriches the improvement process, broadens participation in the change process, and helps to sustain these efforts over time. ( $\mathrm{J}$ Am Board Fam Med 2010;23:632-639.)

Keywords: Quality of Health Care, Health Services, Depression, Practice Improvement

With the passage of the health reform bill, broad changes under the rubric of the patient-centered

This article was externally peer reviewed.

Submitted 13 August 2009; revised 14 May 2010; accepted 24 May 2010.

From the Center for Research Strategies (KG, PAN) and the Department of Family Medicine, University of Colorado Health Sciences Center (PAN, WPD, DSM), Denver; the Department of Family Medicine, University of Michigan, Ann Arbor (DEN); the American Academy of Family Physicians National Research Network, Leawood, KS (DGG, DSM); and the University of Missouri-Kansas City School of Medicine, Kansas City (AJB).

Funding: This study was funded by a grant from the American Psychiatric Foundation. A consortium of industry supporters, including AstraZeneca International; Eli Lilly and Company; Lilly Foundation; Forest Laboratories, Inc.; Pfizer, Inc.; Sanofi Aventis; and Wyeth provided an unrestricted educational grant to the American Psychiatric Foundation for this research.

Conflict of interest: none declared.

Corresponding author: Kaia Gallagher, $\mathrm{PhD}$, Center for Research Strategies, 225 East 16th Avenue, Suite 1150, Denver, CO 80203 (E-mail: Kaia.gallagher@crsllc.org). medical home are being considered and tested in primary care practices. ${ }^{1-4}$ Early reports from these demonstrations describe the magnitude of effort required in small and medium-sized family practices to implement the challenging structures and processes required for transformation to a patientcentered medical home. ${ }^{5-7}$ It is also clear that there is not a single pathway to success in this transformation. ${ }^{6,8}$ The diversity among primary care practice settings makes it unlikely that one formula will work for all, and time and resource constraints along with the growing complexity of comprehensive patient care serve to constrain improvement efforts even among the most motivated practitioners.

Barriers to improvement change efforts include staff resistance, ${ }^{9}$ staff turnover, ${ }^{10,11}$ time constraints, ${ }^{9,12,13}$ information technology challenges, ${ }^{9}$ and the lack of reimbursement for the delivery of 
care for chronic diseases. ${ }^{13-15}$ Although some positive changes have been reported, particularly in the delivery of services, not all interventions have resulted in statistically significant results. Moreover, follow-up studies show that these improvement efforts are not always sustained. Given the variability among primary care practices, ${ }^{16}$ more flexible approaches that embody the concepts of high-performing teams and effective collaboration are now being recommended. Positive improvement outcomes have been found to be more likely to occur when all practice staff are able to participate in decisions ${ }^{17}$ and when improvement teams incorporate a variety of stakeholders with different perspectives. ${ }^{18}$ Having a practice vision, mission, and values statement guide the improvement process, as does setting aside time for learning and reflection. ${ }^{18}$ Practice change is also influenced by the motivation of key stakeholders to achieve change, the availability of resources for improvements, outside factors that encourage change, and opportunities for changes to be implemented. ${ }^{19}$

This analysis examines how small, independent primary care practices without a formal quality improvement program can implement change management using a team approach with 2 coleaders, each in a different professional role, to institute changes in primary care settings. Compared with many interventions that rely on outside facilitators, ${ }^{18,20,21}$ this study demonstrated the feasibility of using a modified improvement collaborative model to train and support practice staff in basic change management strategies ${ }^{22}$; a follow-up report has confirmed that most practices were continuing to use depression care improvements 3 years after the beginning of the intervention. ${ }^{23}$ This analysis enhances our understanding of how the 2 coleaders collaborated and contributed to these results and suggests an approach that can be adapted to independent practice settings.

\section{Methods}

The National Depression Management Leadership Initiative was designed to promote improvements in the management of depression and to implement a process of improvement changes that could be integrated into practice settings. ${ }^{23}$ Support for the project was provided by the Foundations of the American Psychiatric Association and American Academy of Family Physicians (AAFP), with unre- stricted grants from 6 pharmaceutical companies. The protocol was approved by institutional review boards from the University of Missouri-Kansas City Social Sciences, the AAFP, and the University of Michigan.

\section{Participants and Sites}

Eighteen primary care practices were recruited by the AAFP National Research Network and the American College of Physicians' national research network. Attempts were made to recruit practices from both networks that represented a variety of sizes, organizational structures and affiliations, and populations served. Practices had an average of 4.7 clinical staff members. We sought to identify practices that had the autonomy to implement change without seeking approval from a higher administration. Nine family medicine and 9 general internal medicine practices joined the project. Two practices subsequently withdrew from the study.

\section{The Intervention: Overview of the National Depression Management Leadership Initiative}

As part of the National Depression Management Leadership Initiative, improvement teams were designed to be championed by 2 coleaders: one a physician and the other a nonphysician. Although conventional wisdom acknowledges the importance of a team approach to quality improvement, this project specifically engaged physician and nonphysician champions as equals in the change process.

Our intervention was designed around a series of 3 weekend-long learning sessions based on principles of the Reflective-Adaptive Process (RAP) model of practice change. $^{22}$ The general principles of the RAP model are shown in Table 1. This model incorporates iterative rapid tests of change cycles to identify priority improvement opportunities, to consider potential solutions, to test these options, and to reflect on the impact of these changes. The model also stresses the importance of interactions and relationships of all practice members in implementing change.

For specific clinical improvements in depression care, the practice coleaders were encouraged to implement a progressive series of changes including screening/case finding, monitoring, tracking, and case management, all focused around the 9-item Patient Health Questionnaire as a tool to facilitate these steps. In addition, practices were encouraged to implement depression self-management strategies with patients. Previous reports have described the success 


\begin{tabular}{lc}
\hline RAP Principle & Application in the Current Study \\
\hline $\begin{array}{l}\text { Each practice setting is assumed to be } \\
\text { unique in terms of mission, } \\
\text { underlying priorities, history, } \\
\text { relationships, and overall practice } \\
\text { context. }\end{array}$ & $\begin{array}{c}\text { Practice champions were individually selected by the participating practices and } \\
\text { included a physician and non-physician who, in turn, were charged with } \\
\text { shepherding change within their practices. }\end{array}$ \\
$\begin{array}{l}\text { All staff members within a practice are } \\
\text { seen as interconnected and }\end{array}$ & $\begin{array}{r}\text { Improvement teams were recruited by the practice champions and included } \\
\text { staff with varying responsibilities and positions within the practice. }\end{array}$ \\
$\begin{array}{l}\text { relationships and functions. } \\
\text { Relationships among practice staff are } \\
\text { critical to practice effectiveness. }\end{array}$ & \\
$\begin{array}{l}\text { The "health" of a practice can be } \\
\text { characterized by its ability to change } \\
\text { adaptively in response to a wide } \\
\text { variety of environmental challenges. }\end{array}$ & $\begin{array}{c}\text { The improvement teams were presented with a specific menu of depression } \\
\text { change options, but chose for themselves the types of improvements that } \\
\text { would be considered. } \\
\text { the change process. }\end{array}$ \\
$\begin{array}{l}\text { Dividing change into a series of smaller } \\
\text { bites is likely to result in greater } \\
\text { success as compared with trying to }\end{array}$ & $\begin{array}{c}\text { Conflict resolution skills were conveyed to the practice champions during } 3 \\
\text { change too much too suddenly. }\end{array}$ \\
\hline
\end{tabular}

of the practices in implementing and sustaining these improvements. $^{22,23}$

At the beginning, each practice identified 2 coleaders, a physician and nonphysician, who attended the learning sessions and were charged with implementing the project. The nonphysician coleaders who were selected to participate varied in their roles and professional backgrounds: 44\% were nurses (including 2 advanced practice nurses), $19 \%$ were office managers, $13 \%$ were medical assistants, and $24 \%$ served in other administrative and support roles. Representatives from all participating practices attended each of the 3 learning sessions.

After the first learning session, the coleaders established an improvement team in their practices, consisting of 7 to 9 team members. ${ }^{24,25}$ The coleaders served as "facilitators" of their local change process. The improvement teams were encouraged to recruit team members with different skills, experience, knowledge, and viewpoints. Particular attention was given to recruiting those staff members whose jobs would be directly affected by the processes under study.

\section{Data Collection}

Extensive qualitative data were gathered throughout the initiative, including telephone interviews with both coleaders at baseline, between each of the learning sessions, at the initiative midpoint, 6 months after the final learning session, and a follow-up interview 26 months after the final learning session. The telephone interviews were based on structured interview guides and were recorded and transcribed. Systematic observations were recorded as field notes during the 3 learning sessions. These field notes included detailed observations from small group discussions held during all 3 learning sessions. Additional qualitative information was available, including improvement team meeting minutes, journals of practice champions, documentation of improvement plans undertaken, and emails with investigators. Finally, field notes were made during 2 conference calls held with the coleaders toward the last phase of the initiative. In addition, as part of the 3-year follow-up, telephone interviews were conducted with one or both coleaders from each of the participating practices. Both close- and open-ended questions were asked regarding the tasks assumed by each coleader, the way in which they defined their roles, and their experiences with the improvement processes. This rich database captured the change efforts reported by the coleaders as well as the observations they shared within small groups.

\section{Data Management and Analysis}

In all, 236 primary documents were incorporated into a database and coded using Atlas.ti software (Atlas.ti Scientific Software Development GmbH, 
Berlin, Germany). An additional 78 documents were scanned and made available for analysis. All textual material was coded according to categories representing practice site, time frame, change process, and depression care. For the purposes of this analysis, additional coding templates assessed how the physician and nonphysician coleaders defined their goals for the project, how they perceived their roles, the improvement barriers they identified, and the team functions they performed.

\section{Results}

We have previously reported the depression improvements implemented in the participating practices and the ability of most practices to sustain those improvements over time. ${ }^{23,26}$ The current analysis suggests that the differentiated but coordinated roles of the 2 coleaders contributed to the practices' success. The Appendix provides a brief (de-identified) case summary of one of the participating practices.

\section{Differentiation of Practice Champion Roles}

Although the study team anticipated that the 2 coleaders would share the responsibility for implementing changes after the learning sessions, we could not predict how this would actually occur and we did not specify how the coleaders should work together. During the course of the project, a clear division of roles emerged in most practices. We therefore focused our observation and analysis on the role differentiation that evolved as the project proceeded. Data coded from the learning session debriefing sessions and verified by the 6 research team members showed that the physician champions focused on the specific changes suggested for depression care whereas the nonphysician champi- ons became the process managers of the improvement teams. In the experience of the improvement teams, these improvement considerations were complementary and served to reinforce the types of changes, both clinical and nonclinical, necessary to support improved depression care. This role differentiation manifested itself not only during the implementation of the change process but also in how the coleaders perceived and understood barriers to change. Confirmation of this pattern of role differentiation was affirmed during follow-up interviews conducted 26 months after the intervention.

After each learning session the research team reviewed field notes from the debriefing sessions and developed preliminary observations about the team structures and coleader roles. Questions included in the follow-up interviews sought to confirm these preliminary hypotheses through both close- and open-ended questions. Table 2 summarizes the results from the interviews with each of the coleaders as further validated by the research team. The results demonstrate how the coleaders reported sharing 6 specific tasks related to their improvement teams and the ways in which the physician and the nonphysician coleaders differentiated their roles. Although there was variation among the practices, the tasks that were primarily the responsibility of the nonphysician champions were (1) arranging meeting times and logistics; (2) acting as the facilitator for the meetings; (3) coordinating the work of the improvement team between meetings; and (4) following up on any actions that needed to be taken between the meetings. Based on their own descriptions of their roles, the nonphysician coleaders were also more attuned to ensuring that everyone's voice was heard and to improving relationships among staff from

Table 2. Division of Tasks among Non-Physicians and Physicians by Number of Practices* $(\mathrm{n}=14)$

\begin{tabular}{|c|c|c|c|}
\hline & $\begin{array}{l}\text { Physician } \\
\text { Coleader }\end{array}$ & $\begin{array}{l}\text { Shared by Physician and } \\
\text { Nonphysician Coleaders }\end{array}$ & $\begin{array}{l}\text { Nonphysician } \\
\text { Coleader }\end{array}$ \\
\hline Recruiting team members & 2 & 6 & 6 \\
\hline Arranging for meeting times and logistics & 2 & 2 & 10 \\
\hline Setting priorities for issues the improvement team would address & 5 & 7 & 2 \\
\hline Acting as the facilitator during meetings & 6 & 2 & 6 \\
\hline $\begin{array}{l}\text { Coordinating the work of the improvement team between } \\
\text { meetings }\end{array}$ & & 3 & 11 \\
\hline $\begin{array}{l}\text { Follow up on any actions that needed to be taken between the } \\
\text { meetings }\end{array}$ & & 5 & 9 \\
\hline
\end{tabular}

*Data are missing for 2 practices. 
different parts of the practice. The physician coleaders focused on the clinical aspects of the initiative, particularly learning about depression care and how it might be improved. Physician coleaders frequently assumed a leadership role in convening the improvement teams, setting priorities for the issues that the improvement team would address, and facilitating the meetings. In larger practice settings they also described their role as one of sharing information from the improvement team with other physicians in the practice. By the end of the initiative, more than half of the physicians also acknowledged that the initiative had been useful in improving the "process" by which patient care was delivered, either through improved communication, greater teamwork, or enhanced practice efficiency.

Although both the physician and the nonphysician coleaders expressed interest in content and process issues related to the improvement teams, their perspectives were distinctly different. The physicians had a more limited view on empowering staff whereas the nonphysician coleaders intentionally sought to create broader involvement for all staff members, even those who had not traditionally been involved in change processes.

"It was interesting [as a physician] having peers who were primarily [not medical doctors]. We needed buy-in from this group to do this screening so the other non-MD [practice champion] recruited the team and tried to influence advisory staff to support us having meetings."

"[The non-physician champion] did more of it. Her leadership role in the clinic involved mostly administrative duties. So she was working about $60 \%$ to $80 \%$ administrative time and could devote to that. And also, she was supervising those people that would be participating."

\section{Complementary Views of Barriers and Challenges}

Interview findings confirmed that the different perspectives of the physician and nonphysician coleaders were complementary and encompassed a broader range of barriers and challenges than either of them could individually address. The physician coleaders were very aware of the challenges inherent in providing depression care, such as finding time to address depression when this care is often not reimbursed by insurance companies. They were also concerned about making changes to depression care in light of other competing priorities within the practice, and they initiated conscious efforts to solicit support from fellow clinicians for specific depression care improvements. In contrast, nonphysician coleaders were more likely to struggle with issues related to creating and sustaining the improvement team and commented more frequently on the bureaucratic challenges they faced in finding time for the meetings.

"I think it took both of us. ... we both brought different skills to the table. We see problems and barriers in different ways. I focus so much on clinical things and [the non-MD champion] has a bigger picture of how the clinic works overall. I think we also had different kinds of credibility with the staff and ... worked together to bring the group together, even the [doctors] and other staff."

\section{Evolution of the Improvement Team Process}

During the 26-month follow-up interviews, the coleaders commented on the value of the improvement team process and the ways in which they adapted it to meet their needs. At the time of the follow-up, 9 of the 15 practices that were contacted had adapted the change process to their practice circumstances.

"The improvement team continues-before we'd have a big-deal staff meeting-now we have it more regularly; we don't collect problems, we deal with them sooner; we have trouble-shooting teams. We get together and have a quick meeting in the morning [and] if we can't resolve it we bring it to the big staff meeting."

One small practice expanded the improvement team to include all members of the practice.

"We're a small office-we don't have a team. Smaller groups... like the back office and the MAs will meet individually to define individual issues, then we meet as one big improvement team."

In another practice, the nonphysician coleader basically took charge of the improvement team process and did most of the work. Specifically, she organized the team membership and meeting schedules and kept the group on task. During an interview, the coleader said that other staff resisted, saying things like, "who elected you the boss?" The coleader persisted to overcome much of this early resistance and was ultimately successful in continuing the improvement team processes.

\section{Discussion}

Our results suggest that the coleaders of change efforts are able to develop compatible roles and move a change process forward in small, indepen- 
dent primary care practices. It seems that by working together they were able to overcome some of the challenges associated with change efforts, such as a lack of leadership, ${ }^{27}$ limited organizational support for improvement, ${ }^{9,12,27,28}$ the need for ongoing communication, ${ }^{29}$ and the limited involvement of all members of a patient care continuum in the quality improvement efforts. ${ }^{27,30}$ The learning sessions raised the awareness of both coleaders to the difficulty of making and sustaining change and provided them with tools to address resistance to change in their practices. The physicians gained an appreciation of the limitation of a "just do it" approach, and the nonphysicians gained a deeper appreciation of the power of a team in mobilizing the diverse perspectives in a practice that are not usually incorporated effectively into a change process. Complexity science underscores the value of having diversity among change agents; individuals with different backgrounds and identities provide independent and broader views of change options within a practice. Involving diverse partners in decision making about practice change enriches the options that can be considered. ${ }^{24,31}$ Different change agents offer varying perspectives on potential practice improvements, such as examining current practice values, processes, or needs. Feedback from varied practice staff can serve to challenge current perceptions and to identify a varied array of options for change. ${ }^{32}$ The unique lessons learned from this intervention focus on the value of a coleader structure that empowers both leaders to work synergistically to promote and sustain improvement team processes.

\section{Challenges and Lessons for the Future}

Creating and sustaining change in busy, independent primary care practices is a challenging undertaking. The experience of the Improving Depression Care Initiative is that structuring an improvement team process can help to institutionalize and sustain change. The ongoing functioning of these improvement teams is facilitated when there are 2 coleaders who have varied skills and who can work together to create and maintain these teams. When the coleaders include both a physician and a nonphysician, important team functions can be effectively shared. Physicians tend to be attuned to clinical issues, and nonphysician coleaders can focus on process concerns, such as ensuring that the mem- bers of the improvement teams are broadly representative and empowered. Through this initiative, all coleaders became more aware of the complex nature of change processes, the value of structured time for team reflection, and the ways in which changes in depression care can be tested before being fully integrated in the practice as a whole. By diversifying the leadership of these teams and empowering nonphysician staff to become part of the change process, the types of improvements that were tried and ultimately adopted were more fully embraced and integrated among all staff members within the participating practices.

\section{References}

1. Rosenthal TC. The medical home: growing evidence to support a new approach to primary care. J Am Board Fam Med 2008;21:427-40.

2. Bodenheimer T, Grumbach K, Berenson RA. A lifeline for primary care. N Engl J Med 2009;360:2693-6.

3. Fisher ES. Building a medical neighborhood for the medical home. N Engl J Med 2008;359:1202-5.

4. Iglehart JK. No place like home-testing a new model of care delivery. N Engl J Med 2008;359:1200-2.

5. Crabtree BF, Nutting PA, Miller WL, Stange KC, Jaén CR. Summary of the National Demonstration Project and recommendations for the patient-centered medical home. Ann Fam Med. (in press).

6. Nutting PA, Crabtree BF, Miller WL, Stewart EE, Stange KC, Jaen CR. The journey to the patientcentered medical home: a qualitative analysis of the experiences of practices in the National Demonstration Project. Ann Fam Med 2010;8(Suppl 1):S80-90.

7. Nutting PA, Crabtree BF, Stewart EE, et al. Effect of facilitation on practice outcomes in the National Demonstration Project model of the patient-centered medical home. Ann Fam Med 2010;8(Suppl 1):S33-44.

8. Miller WL, Crabtree BF, Nutting PA, Stange KC, Jaén CR. Primary care practice development: a relationship-centered approach. Ann Fam Med 2010; 8(Suppl 1):S68-79.

9. Meredith LS, Mendel P, Pearson M, et al. Implementation and maintenance of quality improvement for treating depression in primary care. Psychiatr Serv 2006;57:48-55.

10. Goldberg HI, Neighbor WE, Hirsh IB, Cheadle $\mathrm{AD}$, Ramsey SD, Gore E. Evidence-based management: using serial firm trials to improve diabetes care quality. Jt Comm J Qual Improv 2002;28:155-66.

11. Randolph G, Fried B, Loeding L, Margolis P, Lannon C. Organizational characteristics and preventive service delivery in private practices: a peek inside the "black box" of private practices caring for children. Pediatrics 2005;115:1704-11. 
12. Miller PM, Stockell R, Nemeth L, et al. Initial steps taken by nine primary care practices to implement alcohol screening guidelines with hypertensive patients: the AA-TRIP project. Subst Abus 2006;27: 61-70.

13. Goff DC Jr, Gu L, Gantley LK, Parker DG, Cohen SJ. Enhancing the quality of care for patients with coronary heart disease: the design and baseline results of the hastening the effective application of research through technology (HEART) trial. Am J Manag Care 2002;8:1069-78.

14. Haase R, Russell S. Improving diabetes care and outcomes in a rural primary care clinic. Jt Comm J Qual Patient Saf 2006;32:246-52.

15. Whelan DJ. Heart failure disease management: implementation and outcomes. Cardiol Rev 2005;13: 231-9.

16. Litaker D, Tomolo A, Liberatore V, Stange KC, Aron D. Using complexity theory to build interventions that improve health care delivery in primary care. J Gen Intern Med 2006;21(Suppl 2):S30-4.

17. Hung DY, Randall TG, Cohen DJ, Tallia AF, Crabtree BF. Productivity and turnover in PCPs: the role of staff participation in decision-making. Med Care 2006;44:946-51.

18. Stroebel CK, McDaniel RR, Crabtree BF, Miller WL, Nutting PA, Stange KC. How complexity science can inform a reflective process for improvement in primary care practices. J Qual Patient Saf 2006; $31: 438-46$.

19. Cohen DJ, Crabtree BF, Etz RS, et al. Fidelity versus flexibility: translating evidence-based research into practice. Am J Prev Med 2008;35(5 Suppl): S381-9.

20. Goodwin MA, Zyzanski SJ, Zronek S, et al. A clinical trial of tailored office systems for preventive service delivery. The Study to Enhance Prevention by Understanding Practice (STEP-UP). Am J Prev Med 2001;21:20-8.

21. Crabtree BF, Miller WL, Tallia AF, et al. Delivery of clinical preventive services in family medicine offices. Ann Fam Med 2005;3:430-5.

22. Nease DE Jr, Nutting PA, Dickinson WP, et al. Inducing sustainable improvement in depression care in primary care practices. Jt Comm J Qual Patient Saf 2008;34:247-55.

23. Nease DE Jr, Nutting PA, Graham DG, Dickinson WP, Gallagher KM, Jeffcot-Pera M. Sustainability of depression care improvements: success of a practice change improvement collaborative. J Am Board Fam Med 2010;23:598-605.

24. McDaniel RR, Walls ME. Diversity as a management strategy for organizations: a view through the lenses of chaos and quantum theories. J Manag Inquiry 1997;6:363-75.

25. McDaniel RR Jr, Driebe DJ. Complexity science and health care management. Adv Health Care Manag 2001;2:11-36.
26. Main DS, Graham D, Nutting PA, Nease DE, Dickinson WP, Gallagher K. Integrating practice change processes into quality improvement of depression care: a report from the National Depression Management Leadership Initiatives's Improving Depression Care project. Jt Comm Qual Patient Saf 2009; 35:351-7.

27. Nelson EC, Batalden PB, Huber TP, et al. Microsystems in health care: Part 1. Learning from highperforming front-line clinical units. Jt Comm J Qual Improv 2002;28:472-93.

28. Goldzweig CL, Parkerton PH, Washington DL, Lanto AB, Yano EM. Primary care practice and facility quality orientation: influence on breast and cervical cancer screening rates. Am J Manag Care 2004;10:265-72.

29. Wroth TH, Boals JC. 4th application of qualityimprovement methods in a community practice: the Sandhills Pediatrics Asthma Initiative. N C Med J 2005;66:218-20.

30. Larsen DL, Cannon W, Towner S. Longitudinal assessment of a diabetes care management system in an integrated health network. J Manag Care Pharm 2003;9:552-8.

31. Miller WL, McDaniel RR Jr, Crabtree BF, Stange KC. Practice jazz: understanding variation in family practices using complexity science. J Fam Pract 2001;50:872-8.

32. Ruhe MC, Weyer SM, Zronek S, Wilkinson A, Wilkinson PS, Stange KC. Facilitating practice change: lessons from the STEP-UP clinical trial. Prev Med 2005;40:729-34.

\section{Appendix}

Newport Primary Care is a primary care practice in a network of 5 practices owned by Valley Medical Health Medical Center. Health care is provided by 2 family physicians, a family nurse practitioner, 2 general internists, and a pediatrician. The practice has been considered a leader in the network for improving chronic care. Major quality initiatives are started from the organizational level, but each practice is expected to implement change at their own pace and in a manner consistent with their circumstances. At the beginning of this initiative, Newport was implementing a planned care program for diabetes based on their participation in a state-wide improvement diabetes collaborative. They were implementing an electronic medical record (EMR) and had initiated work on electronic prescriptions and internal messaging, with laboratory ordering and results retrieval on the horizon. Full electronic records were slated for implementation during the next 2 years. 
The 2 practice champions were a family physician and the practice manager. During the baseline interview, Dr. P described their respective roles.

"She's the clinic manager.... she's responsible for managing the staff. I'm the clinical medical director, I have responsibility for the providers. She has responsibility more for the staff and she reports to somebody in administration at the hospital. We try to work together to run the clinic."

As part of this project they shared responsibility for leading the change effort, with Dr. P taking leadership among the clinical staff and Ms. $\mathrm{N}$ coordinating the support staff and dealing with logistic issues. After the first learning session, Dr. P began to introduce use of the Patient Health Questionnaire (PHQ) to the clinicians, encouraging its use initially for screening and detection and then for monitoring depression severity. He also began to introduce changes into the emerging EMR by working to embed the PHQ within the system and developing reporting capability related to patients with depression. Development of the EMR became a much larger problem than anticipated and consumed much of Dr. P's time during the subsequent 2 years. However, his leadership sustained momentum for proposed improvements and eventually resulted in the integration of a planned care protocol for depression into the EMR; his leadership also encouraged clinical staff to use the associated depression tools effectively. Dr. P became the catalyst for disseminating these depression tools to the other clinics in the network.

Ms. $\mathrm{N}$ used the change management skills in several innovative ways. She formed 2 different reflective-adaptive process (RAP) teams within the practice. One was a standing team that dealt with ongoing issues related to the EMR implementation. She also incorporated the RAP into the monthly staff meetings, including the use of ground rules, meeting evaluations, and feedback procedures. This process began to identify new issues to address, for which she set up ad hoc RAP groups. For example, the medical assistants were having trouble using the messaging capability of the EMR in a consistent way. She convened a group consisting of representatives from each major workgroup in the practice. Each elected its own members, who came together for 2 RAP meetings and then reached consensus on how to manage the messaging capability. They shared "the solution" with their workgroups and everyone tried it. Later they reconvened and tweaked the solution, then returned to their respective groups for more feedback. Everyone seemed pleased with how effectively the group was able to solve some problems that had become contentious within the practice. Ms. $\mathrm{N}$ believes the effectiveness of this process was because of the ability of each workgroup to elect their own representatives, who were selected depending on the problem to be addressed. She reported:

"I now have other groups meeting about other issues. We're getting through our agenda faster in clinic meetings. We have smaller breakout teams from clinic level group. Out of [the] employee satisfaction [survey] we were to vote departmentally on 3 of [the] top 5 things to improve and created small improvement teams to work on the issues.... The groups' self-selection resulted in diverse groups. Meetings have changed, because I'm more focused and mindful of the time."

Both coleaders believed their complementary strengths and responsibilities within the practice were an important feature of their ability to bring about improvement changes. According to Dr. P:

"I was probably the one who was most active in doing the implementation of the depression care items. As a physician the others [doctors] would more likely listen to me. I think [Ms. P] was active in the project with change cycle stuff and was really working with all the staff to get buy-in and cooperation. She and I worked together trying to make the whole thing come together." 